\title{
A strategic approach to building online customer loyalty: Integrating customer profitability tiers
}

Article in Journal of Consumer Marketing • December 2006

DOI: $10.1108 / 07363760610712966$

CITATIONS

76

3 authors:

\section{Dennis A. Pitta}

University of Baltimore

88 PUBLICATIONS 1,290 CITATIONS

SEE PROFILE

\section{Danielle Fowler}

University of Baltimore

28 PUBLICATIONS 463 CITATIONS

SEE PROFILE

Some of the authors of this publication are also working on these related projects:

Project

Linking mathematically formal with socio-organisational Requirements Engineering techniques for high quality Information Systems View project 


\title{
A strategic approach to building online customer loyalty: integrating customer profitability tiers
}

\author{
Dennis Pitta \\ University of Baltimore, Baltimore, Maryland, USA \\ Frank Franzak \\ Virginia Commonwealth University, Richmond, Virginia, USA, and \\ Danielle Fowler \\ University of Baltimore, Baltimore, Maryland, USA
}

\begin{abstract}
Purpose - The purpose of this paper is to present a strategic framework to managing online loyalty.

Design/methodology/approach - The paper integrates concepts including a range of recently published (1993-2006) theoretical works in consumer loyalty and ongoing case developments in internet practice.

Findings - Provides information and action approaches to consumer marketers that may increase the success providing want satisfying market offerings. Outlines the costs and benefits of some online customer loyalty building practices. By integrating the literature supporting lifetime customer value with the literature concerned with generating online customer relationships, it provides a pathway to profitable relationships. It also exposes the unintended problems that some online customer loyalty initiatives may create.

Research limitations/implications - The theoretical concepts that form the foundation of the paper appear to have a significant application to consumer marketing but have not been tested empirically.

Practical implications - Uncovers a previously unreported strategy for generating profitable online customer loyalty.

Originality/value - This paper describes the nature and application of customer value tiers to an important marketing process. It offers the potential of increasing marketing success by allowing firms to maximize the value of their scarce service resources by serving profitable customers.
\end{abstract}

Keywords Customer loyalty, Customer relations, Internet shopping, Profit maximization, Electronic commerce

Paper type Conceptual paper

\section{Introduction}

During the 1980 s customer loyalty was on most marketers' minds. Numerous companies spent millions on customer relationship management programs with the goal of building customer loyalty. It is ironic that the concept of customer loyalty is not something that consumers recognize. For most companies the customer or brand loyalty issue is, in behavioral terms, nothing more than repeat purchasing. In fact, many company efforts aim solely at increasing the percentage of repeat purchases among current customers. Supporting this effort, marketing strategists have developed predictive models that show the important profitability effects of increasing the repeat purchase rate among existing customers.

The problem may lay in the current nature of customer relationship management initiatives. The 1-to-1 Marketing concept (Pepper and Rogers, 1993) generated a groundswell

The current issue and full text archive of this journal is available at www.emeraldinsight.com/0736-3761.htm

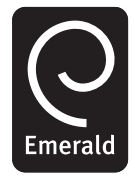

Journal of Consumer Marketing

23/7 (2006) 421-429

Emerald (C) Emerald Group Publishing Limited [ISSN 0736-3761]

[DOI 10.1108/07363760610712966] of interest in getting closer to the customer. The concept is grounded on information technology as a way to capture relevant consumer preferences so that repeat customers might enjoy easier future transactions (Pitta, 1998). The authors note that in a typical service encounter, such as checking into a hotel, numerous questions need to be answered. Thus, guests are conducted through the series of choices that supposedly reveal their true preferences. The genius of the concept is that capturing each of these decisions using appropriate hardware and software identifies the customer and a specific set of preferences. It is assumed that the preferences are somewhat persistent and once they are revealed they tend to remain largely unchanged. In principle, the customer is relieved of the burden of repeating the list of answers each time he or she stays at a hotel in the same chain. Since larger firms with numerous locations realized that each of their units could access the information in their central customer databases, the firms invested heavily in the technology. Thus, technology was a complement, and sometimes a substitute for a personal interaction. The situation is analogous to police forces removing "cops on the beat," police officers who walk through their assigned area and get to know the neighborhood, the law abiding people, and threats to their safety. When police departments put officers in automobiles, they lost the intimacy with their neighborhoods and the people they swore to protect and became less effective at recognizing symptoms of crime before 
crimes occurred. For marketers, losing touch with their customers signals the loss of proactive marketing.

Despite the good intentions of trying to regain lost familiarity, there are a few defects in the system. First, the technology did not always perform flawlessly. Some systems failed to reach the "once and for all" standard. The result required customers to answer that initial list of questions, each time they arrived at a destination, even if they stayed at the chain or the specific hotel before. Even the most unaware consumer would be bored and probably irritated by the repetition. Some have complained about the number of a company's customer service personnel who have asked the same questions over and over.

With many companies embarking on programs to get to know their customers, a second flaw emerged. While companies continued to collect customer data, there was an expectation that the exercise was more of a discrete act than a process. Just because someone ordered a smoking room and a Coke did not guarantee that those selections would not change over time. Humans develop during their lifetimes and change their behavior based on numerous factors. To be really effective, such programs require continuous refreshing of customer preferences. They also should be based on a clear understanding of the elements that comprise customer loyalty.

Perhaps the most important focus should be the "right" customer. Organizations must not only boost repeat purchases and customer satisfaction, they need to discriminate among their customer base. There is a recent awareness that customers are not only different in terms of their needs but deliver different amounts of profitability over their lifetimes. When firms fail to focus on customers who will increase profit and reduce costs, they run the risk of working hard with little to show for the effort. Any attempts at building customer loyalty must be based on a foundation of customer profitability.

\section{The core of customer loyalty}

Consumer loyalty seems to be based on a collection of factors. The first is trust. Consumers must trust the vendor or product they encounter. Second, the transaction or relationship must have a positive perceived value greater than that supplied by competitors. Third, if marketers build on the first two factors, they may be able to create a level of positive customer emotional attachment. That emotional response may be commitment to their brands that is resistant to change. Each of the factors requires some discussion.

\section{Trust}

Much of the customer loyalty literature has attempted to define what the concept entailed. Numerous researchers have focused on the elements that support and grow loyalty. As a result there is a list of concepts that have been studied in isolation and in combination with others. Trust, has been emphasized as a determinant of customer loyalty (Schlosser et al., 2006; Smith, 2002; Reichheld et al., 2000a) throughout the literature. Trust is vital in situations in which informational cues are incomplete. In a world of perfect knowledge, trust is unnecessary. In the real world, it helps reduce perceived risk by lessening the likelihood that a customer will suffer a loss. Essentially, trust bolsters the customer's belief in the likelihood of a positive outcome. The effect may be expressed in terms of a feeling that the vendor will "make things right." In some relationships the initial transaction is based on no previous history and, absent positive word of mouth, is essentially based on faith. After one successful interaction, a consumer will have evidence that the vendor delivers as promised, or not. That evidence supplants faith as a basis for interaction. Early in a relationship, elements such as company or brand name assume increasing importance. They serve as surrogate indicators of probable performance. Thus, international brands such as Toyota have brand equity that bolsters consumers' perception of trust (Ward and Lee, 2000). In fact, in a new relationship, brand or company names and perceptions take on the burden of trust creation. In the online world, trust is still a major concern among online consumers. The prospect of divulging credit card information to an online "stranger" is an e-commerce obstacle to some consumers who in reality could shop securely (Dunn, 2004).

It is known that trust is a living element in a relationship and can grow in strength by successful interactions or be diminished to the point of extinction by a failure to deliver. In extreme cases, when trust is damaged, so is the transactional relationship.

Schlosser et al. (2006) explored three underlying components of trust: the vendor's ability to deliver, benevolence and integrity. Ability, benevolence, and integrity beliefs are acknowledged as conceptually distinct measures of trusting beliefs. Schlosser and her coauthors investigated the effect of web site design investments on consumers' trusting beliefs and online purchase intentions. They found that such investments signal the component of trusting beliefs most strongly related to online purchase intentions: ability. They also found that the effects were strongest when consumers sought to search for products rather than to browse and when purchases involved risk.

There are specific activities that combine to bolster trust. They include overtly ethical activities that can be recognized by customers. Integrity and performance are other key elements. Overall, energetic attempts to provide customers with appropriate levels of information about products and services, privacy, prices, security as well as the company's policies, practices and procedures will increase consumer trust levels (Smith, 2002; Reichheld et al., 2000a). There are ways of operating a business that can be called traditional customer retention practices. They are the bedrock of customer loyalty and include transaction security, trustworthiness, on-time delivery, reasonable prices, product and service performance, as well as follow-up service and support. These elements comprise a set of "trust generating activities." Without these in place and operating, trust building is not possible.

The literature notes that trust is perhaps the one element that must be established early and nurtured throughout the lifetime of the customer relationship. The literature also notes that the economics of an individual transaction are insufficient to insure firm profitability. Customers must buy multiple times for a relationship to be profitable. The lifetime approach takes this economic view into account. The focus on lifetime relationship should not be minimized. Many businesses spend inordinate amounts of time and money trying to attract new customers in contrast to retaining existing customers. For all companies that make serious efforts to attract first time customers, only 40 percent devote equal effort in designing customer retention and repeat purchase strategies. In 
addition, some companies try to maximize individual marketing transactions, ignoring the value of establishing and exploiting relationships with customers. The emphasis seems to be misdirected. Marketers know the economic benefits of customer retention and efforts to boost repeat purchase. There are numerous reports of the positive benefits of increasing customer retention rates on profits. For example, Reichheld et al. (2000a) found that a 5 percent increase in customer retention rates could produce a 25 to 95 percent increase in profits for many companies. That multiplier effect merits attention and action.

Consequently, Zeithaml et al. (2001) emphasize the lifetime customer value (LCV) concept as a means of increasing profitability and success. They suggest that companies should evaluate each customer on his or her LCV and court those with high scores and ignore those with low scores. There are techniques that can be used to accomplish these goals.

\section{Net perceived value}

The relevant research offers a selection of other factors that affect loyalty. Next after trust in developing loyalty is the consumer's perceived sense of value resulting from a transaction or relationship. Perceived value has been defined as a customer's overall evaluation of the benefits versus the costs involved in a marketing context. Specifically, perceived value can be viewed as a broad construct focusing on prices, costs incurred and benefits delivered by a marketer versus competitors. The literature notes that customer satisfaction may be based on a foundation of perceived value but the constructs are different. Different consumers view value in different ways. However, most consider costs and benefits. Looking at benefits and costs helps consider the variety of elements involved in a marketing transaction.

\section{Value}

For some customers, just finding a product is valuable. For example, in the specialty gift market, finding that one gift that perfectly matches a recipient may be a triumph. For others, finance terms or ability to use credit cards is an expected level of service and valued. Other marketing activities such as home delivery of new products and disposal of old ones can determine whether a purchase takes place. Similarly, setup and service may be critical in product categories with a high technological component such as computer or high definition television.

Some but not all customers recognize value in the convenience of their transactions. For some customers, time is a critical element. Thus, mechanisms that reduce the time to search for information about products and vendors, to evaluate that information and make a purchase decision, to speed payment and delivery, and reduce the effort in customer service and satisfaction might be valued. This customer segment may be more sophisticated in its understanding of marketing and its set of preferences and can be targeted for further carefully crafted offers. Specifically, bundling a product of acceptable quality with a set of services aimed at increasing convenience and reducing consumer worry or effort may yield profitable results.

\section{Costs}

The basic value computation would seem to look at benefits versus costs.
They include monetary costs, the well known price of products and services. Costs also include the amount of time, effort, worry, and uncertainty that are involved with a transaction. The idea of "cutting out the middleman" describes a consumer assuming some of the duties of a channel member to get a lower price. For example, pre-paying for an automobile before it is delivered assumes the financial role of a middleman. Similarly, buying in quantity is a middleman practice that should result in lower prices. The practice does not really lower costs, but shifts them to a different set of non-monetary costs. The shifted costs may be considerable and unattractive to particular buyers but is a choice.

The basic conceptualizations not only have elements that pertain to the value a consumer realizes from an interaction but have elements of personal emotional factors as well. Perceived value and emotional factors interact with each other. For example, a consumer who interacts with a retailer can evaluate the outcome using logic. If the interaction is "valuable" in economic or needs satisfaction terms, the consumer may develop a positive emotional response toward the retailer.

\section{The emotional elements}

If a marketer has established trust with particular customers by conducting business focusing on trust generating activities, the stage is set for a deeper relationship. The role of commitment has received special attention (Amine, 1998; Reichheld et al., 2000b). While brand loyalty can be assessed by observing consistent purchases of a brand over a period of time, it is really more than a set of repetitive discrete transactions between consumers and brands. It is not only repeat purchase behavior but also a set of motives that underlie that behavior. Those motives can help to distinguish between spurious loyalty which can be described as inertia and true loyalty which signifies a commitment to the brand or company. This differentiation helps to understand whether a given consumer's repeat purchased will continue (true loyalty) or may stop when a change in the store assortment or the selling conditions occurs (inertia).

Inertia may be rather durable since it is formed based on habits or routines that enable consumers to cope effectively with time pressures and search efforts. Inertia repeat purchasing of a brand appears has been described as habitual behavior to reduce two types of work. The first is mental and involves comparing product or company attributes. The second is physical and focuses on information search activities like visiting stores or searching the internet. Without the bond of commitment, marketers run the risk that apparent consumer loyalty may evaporate when there is a change in the habitual supply conditions, encouraging brand switching. How may true customer loyalty develop? One mechanism involves customers making repeat purchases from a vendor with or without any commitment. Over time, if the vendor takes measures to boost trust, perceived value, and emotional connections, then commitment may follow. Other emotional bonds may assume equal importance.

Recent work on the emotional bonds between customers and brands highlighted a construct that describes the levels of customer engagement. The idea emerged from research done by the Gallup organization. Gallup developed a set of rating scales that measure four critically important emotional states. 
Gallup's research was done professionally and yields efficient and reliable measures. While its strength will vary, emotion is inherent in most consumer decisions. Together, these states represent the strength of the emotional connection existing between a customer and a brand or a company. The measures are labeled: confidence, integrity, pride, and passion. Specifically, confidence is confidence in the brand's promise of benefits. Every product makes claims about the benefits it will convey but consumers have become jaded by too many claims from too many new and improved products. If consumers feel confident about a product or company's benefits, that product or company has achieved a difficult to get accolade.

Consumers must also believe in the brand or company's integrity. A recent list of the ten worst automobiles included the 1977 Honda Accord. Today the Accord is the standard of a valuable and reliable car. In 1977 it was a new product and suffered engine and body problems that were severe. They threatened to sink the model and the company in the American market. Honda took ownership of the issues and fixed each one, mostly at its own expense. That significant investment in its product's reputation paid dividends almost immediately. Honda is a perfect example of a company that stands behind its products and it has a loyal following of customers who believe in the company's integrity.

The higher level emotions are pride in being a customer, and passion for the brand. Pride reflects the degree to which consumers feel appreciated by the company and proud of their personal association with the brand. When consumers seek to wear company logo clothing, or select a company credit card, they manifest that pride in being the company's customer. The Breitling watch company targets some of its owners for exclusive logo merchandise sales. Like the externally branded clothing of the 1990s, Breitling merchandise billboards the corporate name. Exclusive clothing sales to Breitling owners reinforces their pride in being customers.

Passion reflects the belief that the brand is essentially irreplaceable and represents a seemingly perfect fit with the customer's personal needs. It's hard to surpass the consumer passion shown by Harley-Davidson motorcycle owners whose behavior may border on obsession.

The literature has investigated the underlying dimensions of loyalty and loyalty intentions. Some have attempted to map the dynamic mechanism that forms consumer loyalty over time (Johnson et al., 2006). Analysis of responses to the individual items in this set of measures has revealed that customers develop emotional attachment to a brand in a cumulative way, with confidence as the foundation of a brand relationship and passion as the pinnacle.

\section{The role of the transaction}

Another relevant factor in customer loyalty is the interactivity inherent in the buyer-seller relationship (Schlosser, 2000). However, the most valuable views have been multidimensional.

Marketers have long recognized the importance of transactional elements in marketing relationships. Notions of convenience and transactional success have been studied over time. Examples such as the marketing use of transaction cost accounting were attempts to increase customer satisfaction and ultimately loyalty while maximizing profitability. There are numerous variations in terms of transactions. Some, like a visit to a doctor's office may be highly involving and require deep thought and response from patients. Others, such as using a vending machine, are relatively low involvement interactions. The main classification of interest here is the face-to-face versus online transaction.

\section{Face to face transactions in a retail setting}

The face to face $(\mathrm{F} 2 \mathrm{~F})$ transaction environment is an information rich, multimedia communication arena. Potentially, each of the senses can play a part. The typical retail environment may involve informational sources such as point of purchase advertising or video based infomercials, apparent product features, price and warranty information, and human salespeople.

Building customer loyalty in a face to face interaction Face to face transactions involve what is arguably the most powerful communicator in marketing, the product or service. Well-engineered products broadcast their benefits. For example, bicycle stores have a varied inventory that might include examples with titanium and steel frames. Customers who examine and compare the different units will understand the differences in weight readily. Salespeople, knowledgeable about their products and those of their competitors can point out differences, highlight benefits and costs and in doing so offer great aid. In computer terms, a customer can pose "random access" questions to a salesperson and get tailored answers without the need to search through literature or a list of frequently asked questions. Moreover, the professional salesperson can use his or her selling skills to diagnose customer wants and needs and even offer information which the customer did not anticipate asking. During the interaction, customers may form a positive bond with the salesperson, an emotional response. Thus, salespeople who demonstrate honesty, integrity, care and concern can foster a feeling of trust. They can also engender a perception of value by their helpful behavior.

Face-to-face retail interactions may vary greatly. By definition they include the most basic form, customer interactions with a vending machine without other human contact. Even this kind of transaction has some basic elements of the human touch since new vending machines now display questions and express thanks for the business.

However, face-to-face transactions between humans are more complicated. Perhaps the checkout line in a retail store is the least likely human-to-human contact to aid in building a customer relationship. And yet, numerous retailers train their check out personnel to make eye contact with customers, greet them and ask if there is anything further aid they might offer. In repetitive purchase situations like grocery shopping, some customers and check out clerks can develop an acquaintance that is like friendship.

High involvement products require increasing levels of salesperson interaction - "consultative interaction." Helzberg Diamonds, a US jewelry retailer, is known for its high quality gemstones at reasonable prices. Diamonds are high involvement products characterized by high cost, and relatively clear criteria that can aid selection. Helzberg's sales process is highly personalized and may require a trial and error approach that moves a customer to a final choice. Handling that process may be a salesperson's ultimate selling 
challenge. It requires guiding a series of decisions and really understanding the customer's wants. Salespersons' personalities play an important role in building a relationship with customers and Helzberg selects its personnel carefully. During that consultative interaction, the customer has the opportunity to evaluate the salesperson's comments. In general they may be scaled on a number of continua. One relevant scale ranges from "high pressure" to "intelligent advice." If a salesperson can make a sale while conveying the impression of care, concern and offering intelligent, unbiased advice, a positive relationship may result. That relationship may be the basis for strong customer loyalty and repeat purchases. Some Helzberg salespeople have a stable group of customers who return periodically for repeat purchases.

\section{Differences between the face-to-face and online environments}

Early in the evolution of e-commerce, in the early 1990s, the literature discussed terms such as "bricks and mortar" versus "virtual retailers." It became clear that the bricks and mortar competitors had an advantage over the pure internet retailers. Consumers felt more confidence in dealing with a "real" company rather than a comparatively intangible virtual organization. Consumer fears that some internet stores were in actuality ghost storefronts with no inventory and little reputation to defend sometimes were realized. Some consumers lost money when undercapitalized retailers went bankrupt. At the time, bricks and mortar retailers who started internet stores had an instant advantage. Their "clicks and mortar" retail operations had the confidence enhancing real store backing up the benefits of their internet operations. The situation demonstrated that trust is easier to generate for an existing store brand name. A similar situation exists for products.

Danaher et al. (2003) compared the brand loyalty of grocery products for closely matched samples of brands purchased either online or offline. The results were straightforward. They found that for purchases made offline, brand market share is not related to the differences in brand loyalty. However, for online purchases a comparison of actual with model-estimated brand loyalty shows that "excess brand loyalty" exists. In particular, greater brand loyalty is observed for brands with high market share, and vice versa for low share brands.

There is strong evidence of higher brand loyalty for online purchases compared with offline. The findings are consistent with those of Degeratu et al. (2000) who found that brand name was important in the sense that a "strong" brand, characterized by a large market share, did better in an online environment compared with a "weak" brand, characterized by a low market share. Danaher et al. (2003), offer possible explanations for this phenomenon. They include:

- online shoppers may infer product quality from the brand name and the greater relative salience of the brand name online compared with offline means that consumers are likely to place more emphasis on the importance of brand name when shopping online (Moore and Andradi, 1996); and

- buying a well-known rather than a lesser-known brand online has less perceived risk (Ernst \& Young, 1999).
One or both of these reasons are plausible explanations for the finding that online brand loyalty for high market share brands exceeds that of a traditional shopping environment, with the reverse effect for low share brands.

\section{The nature of online transactions}

Commerce on the internet, or e-commerce, has experienced rapid and continued growth over time. Online shoppers are attracted by the ease with which they can find products on the internet, the detailed product information available, and the variety of choices offered. The economics of e-commerce make it easy for vendors to do business online and too many smaller retailers have started internet operations. The result is retailer information clutter. Consumers have demonstrated a tendency to bypass these problems by relying on branded products or themselves (Pitta and Fowler, 2005). The phenomenon, if widespread, could limit the success of new product introductions via the web. Ernst \& Young reported that 69 percent of those surveyed stated that brand names play a significant role in their online buying decisions. Thus, marketing through established brands may be required on the internet, even though consumers' cost of information gathering seems quite low.

There is speculation about the source of the differences between online and offline purchases. Compared to communications with the mass media, internet communications feature enhanced interactivity which empowers customers. They can decide how to approach the information. They can decide what to look at and what to ignore and how to evaluate it. In this context, interactivity is an invitation to choose among different message and product alternatives. While the control is in the hands of the consumer (Schlosser, 2000), one of the glaring contrasts between the online and face-to-face retail environments is the relative lack of interactivity online.

In an online transaction there are no face-to-face props to aid in consumer decision making. As a result, consumers tend to rely on substitutes and analogs to help them make choices. Over time, they tend to increase their experience with online companies as well as their search proficiency and need to rely less on brand names (Ward and Lee, 2000)

\section{Building customer loyalty online}

Marketing managers must establish consumers' trust in a variety of contexts. The specific case of computer-mediated environments such as the internet is particularly difficult (Naquin and Paulson, 2003). One approach involves explicit statements about the security of customers' personal data. However, evidence on the effectiveness of such statements is mixed. Some research has shown that such statements help instill consumer confidence in e-commerce sites (Palmer et al., 2000). In contrast, others suggest that they are not necessarily the most important predictor of online trust (Montoya-Weiss et al., 2003). Findings from a recent large-scale study suggest that consumers use "surface" elements, such as web site design (Fogg et al., 2002) in judging security and trust. Schlosser et al. (2006) found that investments in web site design can boost trusting beliefs and online purchase intentions. Other web site design elements can aid in relationship building.

One innovative relationship-building example comes from the UK. Online travel services have exploited the internet's 
strengths such as ease of search and matched them to the specifics of travel. Travel services require information rich communications ranging from schedules to destination details and terms of service. The information load can be overwhelming to a novice traveler. Online, several major travel services vie for dominance in the marketplace using standard website design features to lure customers. In contrast, a group of UK travel agents has designed its website to deliver immediate primary contact with a real person. The UK travel agents provide a toll free number at the beginning of an online transaction to convey the visitor directly to a helpful human. This helps agencies with a limited internet presence and establishes a human bond immediately.

Another example from the travel industry comes from the USA. In the US airline industry, retirees can be the human being at the other end of the line. Technology allows individuals to work from home and be available for extended hours. Southwest Airlines has a number of customer service agents who work from homes all over the USA. They are scattered across the four continental time zones and Hawaii and comprise a six-hour time zone window. The agents can offer extensive around the clock coverage. The retiree agents are well trained and selected for personality and helpfulness. For many travelers, a friendly grandparent on the other end of the line is comforting and relationship building.

The travel industry offers yet another example that online marketers should consider. Since trust is necessary for any relationship, third party comments can be valuable. Companies like Orbitz solicit customer evaluations and travel recommendations to boost their credibility. These efforts may involve sponsored online forums that invite seasoned travelers to share their personal experiences for the benefit of others. Such online community forums have been shown to alert consumers to opportunities and help them avoid problems. One recent example focused on Easter Island, part of Chile. Travelers warned others to avoid the largest hotel on the island and instead seek one or two smaller venues. The alternatives did not advertise but were excellent. The main hotel advertised heavily but was deemed a place to avoid. The community forum, reachable from the sponsor's web site, adds credibility and value to the sponsor and thus helps build a consumer relationship.

One other technique is to allow customers to join a vendorsponsored "club." Online customer "members" can reap the benefits of "club members only" deals. They can get early warning of impending offers and often get preferential pricing. Since they are readily available to retailers through an online database, these customers provide lower transaction costs. Since they are experienced customers, in the sense that they have purchased from the retailers before, they have a higher probability of purchasing again. Therefore, they are more valuable than customers with no purchase history.

In summary, online marketers face a different challenge than their face to face competitors. They need to generate trust immediately, offer clearly perceived value and establish a long term relationship with selected customers (Smith, 2002). If online marketers are successful in generating brand loyalty, they should treat it as a valuable commodity not to be wasted.

\section{The customer value pyramid}

Marketing textbooks have recognized differences among consumers in their value to firms. Some of the literature deals with heavy versus light users of products and services and notes that heavy users are valuable not only for their contribution to volume and revenue but also for their positive effects on profit. Most firms are aware at some level that their customers differ in profitability, and recognize the " $80 / 20$ rule" - 20 percent of customers produce 80 percent of sales or profit for the company. Empirical studies have supported that rule of thumb. In particular, long-term studies of bank patrons' account behavior and perceptions of service quality, the 80/20 rule was shown clearly (Zeithaml et al., 2001). Specifically, the authors noted that the top 20 percent produced 82 percent of the bank's retail profits, an almost perfect confirmation of the $80 / 20$ rule in this profit setting.

Moreover, the more profitable 20 percent held more sophisticated views of service quality. The highest tier described service quality in terms of three factors: attitude, reliability, and speed. The lowest tier viewed only attitude and speed. In addition, when analyzing the drivers of repeat purchases, the highest tier focused on speed; the lowest on attitude. That evidence offers an opportunity to focus on the more profitable customers with customer loyalty building strategies to which they will respond.

\section{The customer pyramid framework}

As an example Zeithaml et al. (2001) postulated a framework for categorizing customers using a four tier system based on different expected levels of profit. They called the classification system the customer pyramid. Using the customer pyramid is helpful whenever the company has customers that differ in profitability but is delivering the same levels of service to all customers. In these situations, the firm is using limited resources to stretch across a wide group of customers, possibly under-serving its best customers.

Their framework used the names of four metals to indicate value and included the following four tiers, Platinum, Gold, Iron and Lead. Platinum and Gold customers are valued while the Iron and Lead tiers are less attractive.

The Platinum tier describes the company's most profitable customers. They are often heavy users of a product or service and not overly price sensitive. They show a commitment to the firm and seem willing to invest in and try new offerings. The other valuable tier, the gold tier is still attractive. It differs from the platinum tier with lower but still good profitability levels. Gold customers may seek price discounts that limit margins. Also their commitment to the firm is lower than that of the platinum tier. Typically, they may be heavy users of the product category but may value minimizing risk by multi-sourcing rather than working with one company.

The two less attractive tiers, Iron and Lead represent much lower profit potential than others. Iron tier customers are valuable in that they provide the volume needed to utilize the firm's capacity. They should be retained as customers. However, their spending levels, loyalty, and profitability are not substantial enough for special treatment.

In contrast, Lead tier customers represent losses to the company. They tend to cost more than they generate. They may demand more service than they are merit given their spending and profitability. Moreover they may pose a potential threat to the company. Since Lead tier customers expect more than they deserve, they may be dissatisfied with the service they do get and complain to others about the company. 
The usefulness of the customer pyramid classification lies in its focus. While many firms conduct usage segmentation, this approach focuses on a group of variables other than sales that are responsible for profitability of the tiers. It is a robust concept that applies to both online and face-to-face selling situations.

In distinguishing a customers' value, keywords can be important. Labels such as "premier customer," "preferred customer," and "valued customer," can communicate an individual's appropriate service levels quickly. For example, using its own version of the customer pyramid method, Bank of America classifies its customers into three levels roughly equivalent to excellent, good, and average based on their contributions to bank profitability. Each level has access to a range of bank services, with the most profitable customers having the greatest selection and paying the lowest rates. Thus premier customers may have several no fee checking accounts, a free safety deposit box, no charges for currency conversions or money orders, and even preferred rates on loans. In addition, premier customers also are assigned a private banker, available via telephone, who can offer personalized service, increasing the strength of the customer-bank relationship and the potential for profits. Personal contact with a private banker is an expensive service that represents a scarce resource best restricted to the most profitable clients.

The less important preferred customers have to pay for some or all of the services and get higher, less favorable loan rates. They typically do not have access to a private banker. The least important, "valued" customers pay for most services and when applying for loans, get the least favorable, ordinary loan rates. Thus the bank offers a higher level of service to the more profitable customers their own platinum and gold clients. They treat their Iron customers professionally with respect. The Lead clients are missing from the bank's customer service strategy.

Customer pyramid concepts can be applied equally well to online and face-to-face retail situations. The key seems to value both your customers and your products appropriately.

\section{Using the customer pyramid to build online loyalty}

We have seen that the first level of loyalty, trust, plus the second level, perceived value, can lay the groundwork for the third level, relationship building. Presumably, customers who have online purchase relationships with companies have already reached a level of trust. Their perceptions of value may differ depending on the tier that they are in. Zeithaml and her coauthors recognize four different articulations of value: value as low price; value as desired product or service benefits; value as the quotient of quality divided by price; and finally value as the sum of all the received benefits minus the costs.

The first articulation, low price, probably applies to Lead tier customers who want low price even if they have to accept less. Customers who concentrate on desired product benefits without consideration of cost are probably in the Platinum tier. These customers would be satisfied by firms that provide high value, high margin products and services. In between these two are the Gold and Iron customers who are both service and price sensitive. This view supports the reality that some customers are willing to pay for enhanced services and others are not. To support this view, Zeithaml and her coauthors site the numerous levels of express package delivery services offered by FedEx ranging from slow and cheaper to fast and expensive.

Once customers are identified and classified into profitability tiers, firms can attempt to build relationships to enhance customer loyalty while, more importantly, build profitability. For example, Gold tier customers are valuable but can be even more profitable if they morphed into Platinum customers. The requirement is to know the Gold customer very well to build new product offerings that serve the client better. Some strategies that have been used to enhance the relationship include becoming a full service provider. Home Depot is an example of a company that succeeded in turning its Gold customers into Platinum. It opened high end Expo Design Centers that carried exclusive, extensive, and expensive home renovation items targeted to specific Gold customers. It thereby offered a full service alternative to satisfy their needs and found that their purchase volume increased significantly.

Largeart.com, a Maryland-based online provider of large art pieces including murals and sculptures, found that commissioning an artist to create a painting large enough to hang in a bank foyer was the easy part. Getting the piece to an international buyer proved more difficult and became an obstacle to purchase. The solution was to become a full service provider. The company decided to roll the finished painting in a shipping tube, insure it and send it not to the customer, but to a certified framing contractor near the customer. The local framing provider was responsible for unrolling the art at its destination, reframing it, delivering it to the site and hanging the painting for the client. The company now has a network of local experts on contract to provide this technical service around the globe. By providing full service for an unwieldy piece of art, Largeart.com gained valuable customer loyalty and saw improvements in its customers' purchase volume.

Online providers are especially concerned about service problems. Such issues can lead to dissatisfaction and customer relationship extinction. It is imperative that companies learn when service problems occur and resolve them quickly and completely. The Dell computer company sells its systems online. It provides as much information as possible online and uses knowledgeable, well-trained consumer service personnel to guide customers through the design and ordering process. It also offers a service guarantee. Dell assures customers that they will be satisfied or else they receive some form of compensation commensurate with their problem. When a system arrives, Dell service representatives can help with setup via telephone. If there is a problem, such as a defective part, it can be expressed to the customer for installation by a local technician. There are several types of service guarantees. Marketers should choose the type of service guarantee geared to the pyramid tier. The very best customers should get a complete satisfaction guarantee. The worst, Lead tier customers, should get one with fewer features.

One of the best examples of building customer loyalty and moving customers from Gold to Platinum levels involves outsourcing. The practice involves providing an entire function that a customer firm formerly performed for itself. BJ's Wholesale Warehouse is one of the large warehouse discount retailers. It had responsibility for all data processing in each of its stores. While it was successful, an outside vendor consultant offered to integrate each store into a centrally 
processed system based near company headquarters in Massachusetts. The system was much more complex than any BJ's had run internally. The vendor then offered to run and maintain the more extensive system. In a short time, the vendor became the provider of all the company's transaction processing and moved BJ's from a Gold to a Platinum customer. Notably, there was a widespread system failure on Memorial Day, 2006. The vendor's service team solved the problem in less than an hour. While the time lapse seemed like an eternity, and cost the chain lost sales, it was much shorter than the in-house BJ's data processing operation could have delivered. BJ's top management was concerned but upon reflection realized that the glitch would have been a disaster without outside help. Even this problem increased the strength of the customer-vendor bond.

One reason for its value is that outsourcing reduces the nonmonetary costs of providing these services to the client firm, freeing it to concentrate on its core competencies. For example, the expertise and effort required to keep pace with new information technology, threats to security and fixing problems, and keeping qualified staff can become a distraction for a client firm. Once a vendor performs well for a customer, it can bind the customer to the organization and make the customer's business predictable, and increase its value to the company.

\section{Implications for marketers}

While online marketers can make astute decisions that boost consumer trust, increase perceived value and build loyal customer relationships, it should be clear that companies must be selective. In an environment typified by turmoil and scarce resources, marketers must consider whom they wish to serve carefully. In fact, the typical strategies for building online volume may be counterproductive in building attractive customer relationships. In contrast, setting requirements to be a customer may raise a firm's perceived exclusivity, making existing customers proud.

For example, some of the specific techniques for building online loyalty involve electronic coupons and e-mail newsletters that contain special offers. The idea is that customers will respond to special offers that reduce price and thereby increase perceived value. Using a classification system like the customer pyramid offers guidance in the search for profitability. In fact, price reduction offers are a bad idea for lead tier customers. The discounts may be popular with lead customers but they may reduce profitability. There are examples of customers delaying routine purchases in anticipation of a price break, reducing profits further. Moreover, discount offers may be irrelevant to platinum or gold tier customers and should be avoided.

The economics of e-commerce make personal contact too expensive to extend to all online customers. Thus, marketers tend to reject the concept out of hand. However, contact with a human can be valuable and boost company profits. Marketers may wish to use personal contact relationship building strategies only with their most profitable customers. By restricting it to the Platinum or Gold customer tiers, human contact can become affordable and the firm can enjoy its profit enhancing benefits.

Finally, some of the techniques that foster online volume building should be applied very carefully to the customer pyramid. The examples used above like members only clubs pose a danger to profits if applied to lead tier customers. Price discounts may be wasted on them. In contrast, Platinum tier members can be alerted to new purchase opportunities before the general public. If price is not part of the offer, Platinum tier customers may appreciate the advanced notice, which will increase their bond with the marketer.

Another example, sponsored online community forums can offer value if restricted to satisfied customers. Presumably, the Platinum and Gold tier customers are satisfied and will appreciate third party recommendations. The danger, again, is focused on Lead tier customers. They will probably enjoy the lowest level of services and if they find a way to join such a forum, may complain about the sponsor and tarnish the experience for others. The final caveat is that discriminating against Lead tier customers makes economic sense. However, it must be done carefully to avoid angering them and causing further damage.

\section{References}

Amine, A. (1998), “Consumers' true brand loyalty: the central role of commitment", Fournal of Strategic Marketing., Vol. 6, pp. 305-19.

Danaher, P.J., Wilson, I.W. and Davis, R.A. (2003), "A comparison of online and offline consumer brand loyalty", Marketing Science, Vol. 22 No. 4, pp. 461-76.

Degeratu, A., Rangaswamy, A. and Wu, J. (2000), "Consumer choice behavior in online and traditional supermarkets: the effects of brand name, price, and other search attributes", International fournal of Research in Marketing, Vol. 17 No. 1, pp. 55-78.

Dunn, J. (2004), "Survey shows online security perception gap between experts, users", Knight Ridder Tribune Business News, Vol. 17, p. 1.

Ernst \& Young (1999), The Second Annual Ernst \& Young Internet Shopping Study: The Digital Channel Continues to Gather Steam, Ernst \& Young, New York, NY, available at www.ey.com/publicate/consumer/pdf/internetshopping.pdf (accessed October 18).

Fogg, B.J., Soohoo, C., Danielson, D., Marable, L., Stanford, J. and Tauber, E. (2002), "How do users evaluate the credibility of web sites? A study with over 2,500 participants", available at: http://portal.acm.org/citation. cfm?doid = 997078.997097 (accessed December 6, 2005).

Johnson, M.D., Herrmann, A. and Huber, F. (2006), "The evolution of loyalty intentions", fournal of Marketing, Vol. 7 No. 2, pp. 122-32.

Moore, K. and Andradi, B. (1996), "Who will be the winners on the internet?", Fournal of Brand Management, Vol. 4 No. 1, pp. 57-64.

Montoya-Weiss, M.M., Voss, G.B. and Grewal, D. (2003), "Determinants of online channel use and overall satisfaction with a relational, multichannel service provider", Fournal of the Academy of Marketing Science, Vol. 31, pp. 448-58.

Naquin, C.E. and Paulson, G.D. (2003), "Online bargaining and interpersonal trust", fournal of Applied Psychology, Vol. 88 No. 1, pp. 113-20.

Palmer, J.W., Bailey, J.P. and Faraj, S. (2000), "The role of intermediaries in the development of trust on the WWW: the use and prominence of trusted third parties and privacy statements", Fournal of Computer-Mediated Communication, Vol. 5, March, pp. 1-25. 
Pepper, D. and Rogers, M. (1993), The One-to-One Future: Building Relationships One Customer at a Time, Century Doubleday, New York, NY.

Pitta, D.A. (1998), "Marketing one-to-one and its dependence on knowledge discovery in databases", fournal of Consumer Marketing, Vol. 15 No. 5, pp. 468-80.

Pitta, D. and Fowler, D. (2005), "Online consumer communities and their value to new product developers", Fournal of Product and Brand Management., Vol. 14 No. 5, pp. 283-91.

Reichheld, F.F., Markey, R.G. Jr and Hopton, C. (2000a), "The loyalty effect - the relationship between loyalty and profits", European Business fournal, Vol. 12 No. 3, pp. 134-9.

Reichheld, F.F., Markey, R.G. Jr and Hopton, C. (2000b), "E-customer loyalty - applying the traditional rules of business for online success", European Business fournal, Vol. 12 No. 4, pp. 173-9.

Schlosser, A.E. (2000), "Harnessing the power of interactivity: implications for consumer behavior in online environments", in Hoch, S.J. and Meyer, R.J. (Eds), Advances in Consumer Research, Vol. 27, Association for Consumer Research, Provo, UT, p. 79.

Schlosser, A.E., White, T.B. and Lloyd, S.M. (2006), "Converting web site visitors into buyers: how web site investment increases consumer trusting beliefs and online purchase intentions", fournal of Marketing, Vol. 70 No. 2, pp. 133-48.

Smith, A.D. (2002), "Loyalty and e-marketing issues", Quarterly fournal of Electronic Commerce., Vol. 3 No. 2, pp. 149-61.

Ward, M.R. and Lee, M.J. (2000), "Internet shopping, consumer search and product branding", fournal of Product E) Brand Management, Vol. 9 No. 1, pp. 6-20.
Zeithaml, V.A., Rust, R.T. and Lemon, K.N. (2001), "The customer pyramid: creating and serving profitable customers", California Management Review, Vol. 43 No. 4, p. 118.

\section{Further reading}

Pastore, M. (2000), "Internet retailers look toward profitability", InternetNews.com, August 30.

\section{About the authors}

Dennis Pitta is the J. William iddendorf Distinguished Professor at the Merrick School of Business, University of Baltimore. He has authored numerous articles in product management and healthcare marketing. His current research interests are new product development, and the effect of new technologies on marketing.

Frank Franzak is Associate Professor and Chair of the Marketing Department at the Virginia Commonwealth University. His research interests focus on creativity and new product development. In addition, he is engaged in research detailing the relationship between the creative culture in nations and their new product development success.

Danielle Fowler is an Assistant Professor at the Merrick School of Business, University of Baltimore. She is an expert in e-commerce and information technology and its application to business and marketing. Her current research investigates emerging marketing applications for smart cards and other technology.

To purchase reprints of this article please e-mail: reprints@emeraldinsight.com Or visit our web site for further details: www.emeraldinsight.com/reprints 